\title{
Hereditary angioedema caused by C1-esterase inhibitor deficiency: a case report with literature-based analysis
}

\author{
Sufia Athar ${ }^{1 *}$, Noureddine Korichi ${ }^{2}$, Yousra Shehada Siam ${ }^{1}$
}

\begin{abstract}
${ }^{1}$ Department of Obstetrics and Gynecology, ${ }^{2}$ Department of Anaesthesiology, Al-Wakra Hospital, Hamad Medical Corporation, Al-Wakra, Qatar
\end{abstract}

Received: 24 November 2018

Accepted: 29 December 2018

\section{*Correspondence:}

Dr. Sufia Athar,

E-mail: sufia24@rediffmail.com

Copyright: $\odot$ the author(s), publisher and licensee Medip Academy. This is an open-access article distributed under the terms of the Creative Commons Attribution Non-Commercial License, which permits unrestricted non-commercial use, distribution, and reproduction in any medium, provided the original work is properly cited.

\section{ABSTRACT}

Hereditary angioedema (HAE) caused by $\mathrm{C} 1$-esterase inhibitor deficiency is an autosomal-dominant disease caused by a mutation in the $\mathrm{C} 1$-inhibitor gene. It is a rare disease that is often worsened during pregnancy and childbirth. HAE, though uncommon but if untreated it may lead to maternal death. The case report presents the successful management of a 24 years old, G2P1, with hereditary angioedema caused by $\mathrm{C} 1$-esterase inhibitor deficiency. This patient was managed with a multidisciplinary approach by an obstetrician, an immunologist, an anaesthesiologist and a pediatrician. She had an uneventful antenatal period, labor was induced. She had precipitate delivery and soon after delivery had a flare up of the disease. It was successfully managed with fresh frozen plasma and close observation.

Keywords: C1-esterase inhibitor deficiency (HAE-C1-INH), CI inhibitor concentrate, Fresh frozen plasma (FFP), Hereditary angioedema (HAE), Plasma derived human $\mathrm{C} 1$ inhibitor concentrate (pdhC1INH), Pregnancy

\section{INTRODUCTION}

Hereditary angioedema (HAE) caused by C1-esterase inhibitor deficiency has an autosomal-dominant pattern of inheritance. It is characterized by frequent attacks of extensive, localized subcutaneous edema of body tissues. It may involve the extremities, genitalia, face, trunk or submucosal edema of upper airway or bowels. These symptoms may be debilitating. On occasions the flare-ups may be life-threatening when affecting the upper airways. ${ }^{1}$ Women with hereditary angioedema (HAE) are more likely to be symptomatic that men. Hormonal factors as puberty, contraception, pregnancy etc. Play a significant role in the precipitation or worsening of the condition in women. ${ }^{2-4}$ During pregnancy, attack rate may increase. ${ }^{3-5}$ Some studies have demonstrated increase in the attack rates with the subsequent pregnancies. ${ }^{6,7}$ Different effects of HAE on pregnancy and postpartum period have been noted. Some patients have flare-ups while some experience improvement of symptoms. ${ }^{2}$ HAE-C1-INH during pregnancy should be treated according to symptoms in pregnancy and previous history of flare-ups in previous child birth. Before labor and delivery prophylaxis may/may not be indicated; use of plasma-derived human C1-inhibitor concentrate (pdC1INH) for acute attacks or as a short-term preventive treatment for pregnant women is recommended..$^{5,8-11}$

Due to its rare prevalence, there is lack of clinical knowledge in the management of HAE. In countries with very low prevalence of these cases, management is even more challenging. In addition, due to unavailability of the newly recommended drugs for HAE and their safety in pregnancy and lactation, treatment in pregnancy and in post-natal period remains a challenge for the clinicians. ${ }^{10,11}$ In places where the prevalence of HAE is very low and the drugs for treatment of HAE are not available, management of these patients with fresh frozen 
plasma is promising and effective. ${ }^{12-14}$ The case below, presents a pregnant patient with hereditary angioedema, illustrates the symptomatic presentation in her post-natal period and successful treatment with fresh frozen plasma.

\section{CASE REPORT}

A 24 years old female, gravida 2, para 1 had regular antenatal visits to our hospital. She was a known case of hereditary angioedema (C1-Esterase Inhibitor Deficiency). This was diagnosed after she had an attack of the disease in the form of respiratory distress and facial edema after receiving analgesia for a dental procedure. Patient was intubated and hospitalized for a couple of days. She also had a brother and a cousin with the HAEC1-INH.

Her previous pregnancy and post-natal phase were uneventful. In her current pregnancy she was asymptomatic, and her C1-Esterase Inhibitor protein level was low, $82.5 \mathrm{mg} / \mathrm{dl}$ (normal range:195-345mg/dl). Levels of $\mathrm{C} 2$ and $\mathrm{C} 4$ were low while $\mathrm{C} 1 \mathrm{a}$ was normal. In view of HAE-C1-INH, she had planned induction of labor at 40 weeks to avoid complications in labor. She had consultation with pulmonologist, neonatologist and anesthetist during her antenatal period and prior to decision for timing of delivery. The plan was to transfuse fresh frozen plasma before onset of labor to prevent an attack of HAE. Epidural analgesia was also planned. However, after induction of labor with prostaglandin E2 first dose, she had precipitate labor and delivered soon. Her delivery was spontaneous and uneventful without any complications. Within thirty minutes after her delivery, she developed facial itching followed by rashes all over her face and facial edema commenced. Rashes were non-urticarial and serpiginous. Her vitals were stable with no respiratory discomfort. She was assessed by the anesthesiologist immediately for the need of airway support. She received 4 units of fresh frozen plasma. Gradually her symptoms subsided, and she was monitored for next 6 hours in labor room. She had uneventful post-natal period later in the post-natal ward and was discharged home in stable condition after medical and anesthetic consultation. Follow up with immunologist was given. She had an uneventful postnatal period.

\section{DISCUSSION}

The above case presents successful management of patient with C1-INH-HAE with a multidisciplinary approach and hence preventing life threatening complications. HAE appears to have a benign course during pregnancy. However, case reports have described increased incidence and severity of attacks. ${ }^{2-4}$ In some cases, labial edema had been reported as first clinical symptom of HAE attack. This may be followed by perineal edema, hypovolemia and shock. Few studies have reported abdominal symptoms as most common presentation in pregnancy. ${ }^{15}$ The presentation is hence variable and unpredictable.

The diagnosis of HAE in pregnancy is difficult as C1INH levels decrease in normal pregnancy. In addition to $\mathrm{C} 1-\mathrm{INH}$ levels, measurement of $\mathrm{C} 1-\mathrm{INH}$ function, $\mathrm{C} 1$ INH protein and $\mathrm{C} 4$ is recommended. ${ }^{11}$ Women with $\mathrm{C} 1-$ INH-HAE/nC1-INH-HAE during child birth should be monitored closely with multidisciplinary approach in hospital by an obstetrician, an immunologist, an anesthesiologist and a pediatrician along with the HAE specialist (if available) in pregnancy, labor and post-natal period to avoid delays in the management up flareups. $5,10,11$

Vaginal delivery is the preferred mode of delivery to avoid anesthetic risks during cesarean section. Routine prophylaxis in uncomplicated labor is not recommended. In patients with recurrent attacks during pregnancy especially in third trimester and those with anticipated instrumental delivery, prophylaxis should be considered. ${ }^{11}$

Prophylaxis with pdhC1INH is advised before forceps or vacuum extraction or cesarean section. Regional Anesthesia is preferred to endotracheal intubation. ${ }^{10,11}$ In patients with planned and emergency Cesarean pdC1INH prophylaxis is recommended. ${ }^{8,11}$ Epidural analgesia is considered as the analgesia of choice. ${ }^{11}$

HAE, though uncommon but if untreated it may lead to maternal death. ${ }^{6}$ It may also cause fetal and neonatal death. According to International consensus and practical guidelines on the gynecologic and obstetric management of female patients with hereditary angioedema caused by C1 inhibitor deficiency, "Attenuated androgens are contraindicated and should be discontinued before attempting conception. Plasma derived human C1 inhibitor concentrate (pdhC1INH) is preferred for acute treatment, short-term prophylaxis, or long-term prophylaxis. $^{6,10,11}$ Tranexamic acid or virally inactivated fresh frozen plasma can be used for long-term prophylaxis if human plasma-derived $\mathrm{C} 1-\mathrm{INH}$ is not available. No safety data are available on icatibant, ecallantide, or recombinant human C1-INH (rhC1INH) as of now." technique in emergency rooms to immediately treat cases of life-threatening angioedema. Though it is not the drug of choice, but it is fast-acting, effective, relatively safe and easily available in most emergency rooms. At places where pdC1-INH is not available, it can be used for acute flare-ups and short-term prophylaxis as well. ${ }^{12-14}$

Some cases have also been reported to aggravate the symptoms, hence when FFP is used, patients should be closely monitored. WAO recommends at least 72 hours follow up in uncomplicated delivery. ${ }^{11}$ Lactation may also cause aggravation of symptoms and flare up but is still recommended as benefits outweigh the risks. 
In patients with recurrent attacks during lactation and in cases where androgens are introduced, breast feeding should be discontinued. ${ }^{10,11}$ These patients should be given advice on contraception on discharge to prevent unwanted pregnancy, till the diagnosis if confirmed and patient is stabilized. Estrogen has been proved to precipitate attacks, therefore combined contraceptive pills are not indicated and progestogen pill must be preferred for contraception. ${ }^{10,11}$ Evaluation of $\mathrm{C} 1$-INH level and function should be done in post-natal period for newly diagnosed cases in pregnancy/lactation for confirmation of diagnosis. ${ }^{11}$ Family members should be counseled for support at home and to report to Emergency in case any flare-up is noted. ${ }^{11}$

\section{CONCLUSION}

Essentially, diagnosis and management of HAE patients in pregnancy and post-natal period is challenging, notably in places with low prevalence. Early diagnosis and prompt treatment with FFP can be lifesaving. Physicians should be aware of the presentation of the disease and treatment of flare-ups to prevent maternal and fetal morbidity and mortality.

Funding: No funding sources

Conflict of interest: None declared

Ethical approval: Not required

\section{REFERENCES}

1. Bork K, Meng G, Staubach P, Hardt J. Hereditary angioedema: new findings concerning symptoms, affected organs, and course. Am J Med. 2006;119:267-74.

2. Martinez-Saguer I, Rusicke E, Aygören-Pürsün E, Heller C, Klingebiel T, Kreuz W. Characterization of acute hereditary angioedema attacks during pregnancy and breast-feeding and their treatment with C1 inhibitor concentrate. Am J Obstet Gynecol. 2010;203(2):131-e1.

3. Atsushi S, Takayuki F, Tomohiro N. Comparison of the frequency of angioedema attack, before and during pregnancy, in a patient with type i hereditary angioedema. Intern Med. 2018;57:751-5.

4. Riedl MA, Banerji A, Gower R. Current medical management of hereditary angioedema: follow-up survey of US physicians. J Allerg Clin Immunol Pract. 2015;3:220-7.

5. Chen M, Riedl MA. Emerging Therapies in Hereditary Angioedema. Immunol Allerg Clin. 2017;37(3):585-95.

6. Caballero T, Farkas H, Bouillet L, Bowen T, Gompel A, Fagerberg C, et al. International consensus and practical guidelines on the gynecologic and obstetric management of female patients with hereditary angioedema caused by $\mathrm{C} 1$ inhibitor deficiency. J Allerg Clinic Immunol. 2012;129(2):308-20.

7. Ushijima J, Sasaki S, Horiuchi I, Masuko H, Kuwata T. A Case of Pregnancy Complicated with Type 1 Hereditary Angioedema (HAE 1). J Clin Case Rep. 2017;7(924):2.

8. Cimbollek S, López-Serrano MC, Piñero-Saavedra M, Rubio M, Caballero T. Management of pregnancy and delivery in patients with hereditary angioedema due to $\mathrm{C} 1$ inhibitor deficiency. J Investig Allergol Clin Immunol. 2016;26(3).

9. Moldovan D, Bernstein JA, Hakl R, Relan A. Safety of recombinant human $\mathrm{C} 1$ esterase inhibitor for hereditary angioedema attacks in pregnant women. $\mathbf{J}$ Allerg Clinic Immunol. 2018;141(2):AB53.

10. Teresa C, Julio C, Daniela RP, Rosario C. Management of hereditary angioedema in pregnant women: a review. Int J Women's Heal. 2014;6:83948.

11. Maurer M, Magerl M, Ansotegui I, Aygören-Pürsün $\mathrm{E}$, Betschel S, Bork $\mathrm{K}$, et al. The international WAO/EAACI guideline for the management of hereditary angioedema-the 2017 revision and update. World Allerg Organizat J. 2018;11(1):5.

12. Mosier M, Riddle JD. Prophylaxis and Treatment of Hereditary Angioedema with Fresh Frozen Plasma: A Synthesis and Narrative Review. Anesthesia E J. 2018;6:12-7.

13. Green L, Bolton-Maggs P, Beattie C, Cardigan R, Kallis Y, Stanworth SJ, et al. British Society of Haematology Guidelines on the spectrum of fresh frozen plasma and cryoprecipitate products: their handling and use in various patient groups in the absence of major bleeding. Brit $\mathrm{J}$ Haematol. 2018;181(1):54-67.

14. Aleena B, Marc R. Managing the Female Patient with Hereditary Angioedema. Womens Health. 2016;12

15. Cicardi M, Aberer W, Banerji A, Bas M, Bernstein JA, Bork K, Caballero T, et al. Classification, diagnosis, and approach to treatment for angioedema: consensus report from the Hereditary Angioedema Int Working Group. Allergy. 2014;69(5):602-16.

Cite this article as: Athar S, Korichi N, Siam YS. Hereditary angioedema caused by $\mathrm{C} 1$-esterase inhibitor deficiency: a case report with literaturebased analysis. Int J Reprod Contracept Obstet Gynecol 2019;8:741-3. 